\title{
Detection of Bacterial DNA in Serum from Colon Cancer Patients: Association with Cytokine Levels and Cachexia
}

\author{
Jian Zhang ${ }^{1}$, Lei $\mathrm{Mi}^{2}$, Yongjie Wang ${ }^{3}$ and Dianliang Zhang ${ }^{1 *}$ \\ Correspondence: phdzdl@yahoo.com \\ ${ }^{1}$ Department of General Surgery, the Affiliated Hospital of Medical College Qingdao University, 16 Jiangsu Road, Qingdao, 266003, P.R. China. \\ ${ }^{2}$ Department of General Surgery, the Central Hospital of TaiAn City, 29 Longtan Road, TaiAn, 271000, P.R. China. \\ ${ }^{3}$ Department of Thoracic Surgery, the Affiliated Hospital of Medical College Qingdao University, 16 Jiangsu Road, Qingdao, 266003, P.R. China.
}

\begin{abstract}
Background: There is increasing evidence that cancer cachexia patients have high cytokine levels, and bacterial translocation (BT) could increase cytokine secretion. Thus, we sought to investigate the relationship between BT and cancer cachexia.

Methods: We studied colon cancer patients in our ward and healthy outpatient controls. Cancer patients were considered cachectic if they had lost $>10 \%$ of their pre-illness stable weight within 6 months and had serum CRP $>10$ mg/L. Polymerase chain reaction (PCR) was used to detect bacterial DNA in serum from cancer patients and healthy controls. Cytokine levels were assessed using enzyme-linked immunosorbent assay (ELISA).

Results: Bacterial DNA fragments were detected in 12 of 50 patients with cachexia (24.0\%) and in 4 of 50 non-cachectic patients (8.0\%). None of 89 healthy controls had bacterial DNA fragments in their serum. A statistically significant difference was found between cachectic and non-cachectic patients $(p=0.037,<0.05)$ and healthy controls $(p=0.62 \times 10-5,<0.05)$. BT(+) cachectic patients had significantly higher levels of IL-1a, IL-6, IL-8, and TNF- $a$ than healthy controls and BT(-) cachectic patients. CD3+ T, $C D 4+T, C D 4+T / C D 8+T$, and NK cell numbers were significantly lower in colon cancer patients than in healthy controls ( $p<$ $0.05)$, but CD8+ cell numbers were significantly higher in healthy controls than in cancer patients.
\end{abstract}

Conclusions: Our results suggest for the first time that BT may contribute to cancer cachexia.

Keywords: cachexia, bacterial translocation, colon cancer, cytokine, DNA

\section{Background}

Cancer cachexia is a complex metabolic syndrome characterized by marked weight loss, anorexia, asthenia and anemia, inflammation, hypoimmunity, and insulin resistance [1]. Cachexia is responsible for approximately $25 \%$ of deaths in cancer patients [2]. It is responsible not only for poor quality of life and a poor response to chemotherapy, but also shorter survival time, regardless of tumor mass or the presence of metastases; it also interferes with cancer therapies [3].

The mechanism of cancer cachexia remains largely unknown. In humans, there is increasing evidence that proinflammatory cytokines, including tumor necrosis factor alpha (TNF-a), interleukins (IL-1, IL-6, IL-8), and interferon gamma (IFN- $\gamma$ ), may play important roles in cancer cachexia [4-8]. Many etiopathogenisises can increase cytokine secretion, such as alimentary canal obstruction, abdominal operation, radiotherapy, and chemotherapy. However, we noticed that some patients had significant weight loss and high levels of cytokines, but they do not have the factors listed above $[9,10]$. In such cases, we considered that endogenous infection or bacterial translocation from the gastrointestinal tract may play an important role in the occurrence and/or development of cancer cachexia.

The term "bacterial translocation" (BT) can be defined as the passage of bacteria or their products from the bowel lumen across the lamina propria to local mesenteric lymph nodes, and, from there, to distant sites [11]. Several factors have been proposed as promoters of $\mathrm{BT}$, including alterations in gastrointestinal microflora, impairment of the gut barrier function, and deficiencies in host immunity [12].

There is increasing evidence that colon cancer patients have an imbalance in intestinal microflora, mucosal barrier dysfunction, and impaired immunity. If BT occurs, the impaired immune competence of cancer patients would not allow clearance of the translocated bacteria, and the surviving bacteria would propagate and cytokine secretion would be expected to increase.

Given that BT can induce higher cytokine secretion and high levels of cytokines play a significant role in cancer cachexia, the aim of this study was to investigate whether BT was associated with cancer cachexia in colon cancer patients.

(C) 2012 D. Zhang et al; licensee Herbert Publications Ltd. This is an open access article distributed under the terms of Creative Commons Attribution License (http://creativecommons.org/licenses/by/3.0), This permits unrestricted use, distribution, and reproduction in any medium, provided the original work is properly cited. 


\section{Patients and Methods Patients}

The ethics committee of the hospital approved the study protocol. Informed consent was obtained from each patient. Informed consent was also obtained from each healthy control. Consecutive patients with colon cancer admitted to our hospital for surgical treatment during a 12-month period were considered. All cases were ethnically Chinese Han. Patients were divided into two groups, according to severity of weight loss and C-response protein (CRP) levels: cachectic patients and non-cachectic patients. Patients were considered cachectic if they had lost $>10 \%$ of their pre-illness stable weight within 6 months and serum CRP $>10 \mathrm{mg} / \mathrm{L}$. Patients were confirmed as having a colon adenocarcinoma by histopathological examination. Exclusion criteria were: (1)anorexia nervosa, (2)major gastrointestinal disease, chronic heart failure, hepatic failure and renal failure, uncontrolled diabetes, infection, or HIV, (3)antibiotic treatment in the 2 weeks preoperatively, (4) abdominal infection or contamination, (5)surgery, radiotherapy, or chemotherapy during the previous 4 weeks, or (6)intestinal obstruction. We obtained healthy controls from outpatients, matched in terms of age and gender. We obtained blood samples from patients after they were admitted and before any treatment and from the healthy controls for hematological and biochemical studies.

\section{DNA Isolation, Amplification, Sequencing}

We detected bacterial DNA in accordance with a previously described method [16]. Briefly, $200 \mu \mathrm{L}$ plasma was incubated in lysozyme-proteinase $\mathrm{K}$ buffer for $2 \mathrm{~h}$ and placed into QIAamp Spin Columns (Qiagen, Hilden, Germany). A broad-range polymerase chain reaction for the amplification of a conserved region of the $16 \mathrm{~S}$ ribosomal RNA prokaryotic gene was carried out using the following universal primers: 5'-AGAGTTTGATCATGGCTCAG-3' and 5'-ACCGCGACTGCTGCTGGCAC-3'. The primers are located at positions 7-27 and 531-514. The total polymerase chain reaction volume was filtered with QIAquick Spin Columns (Qiagen) to remove remaining primers and analyzed by $2 \%$ agarose gel electrophoresis and UV visualization. The final product was purified by precipitation with ethanol-acetate and analyzed with an ABI PRISM 310 automated sequencer (Applied Biosystems). Sequences obtained were compared with the database of the National Center for Biotechnology Information (NCBI, www.ncbi.nih.gov) using the advanced BLAST search tool.

DNA extracted from $E$. coli as a positive control was used in $P C R$ reactions to determine whether the $P C R$ reaction was successful. Additionally, sterile water and PCR mixtures (without template) were used as negative controls.

The limit of detection of the method was evaluated. One colony from a culture of $E$. coli was diluted up to 100,000 -fold in sterile water. DNA isolation from $200 \mu \mathrm{L}$ of each dilution was performed. DNA yield and purity were measured by reading optical densities at $260 \mathrm{~nm}$ and $260 / 280 \mathrm{~nm}$, respectively. Of each sample, $2 \mu \mathrm{L}$ was included in a PCR reaction.

\section{Quantification of serum cytokines levels}

We used enzyme-linked immunosorbent assay (ELISA) to detect cytokines in serum obtained from cancer patients and healthy controls using Human Quantikine kits (R\&D Systems, Abingdon, UK), according to the manufacturer's protocol. All samples were tested in triplicate and read at $490 \mathrm{~nm}$ with a Thermomax microplate reader (Molecular Devices, Sunnyvale, CA). The lower limits of detection of all cytokine assays were $5-10 \mathrm{pg} / \mathrm{mL}$.

\section{Quantification of peripheral blood T cell subsets and NK cells}

We collected peripheral blood $(2 \mathrm{~mL})$ from all cancer patients and healthy controls; blood samples were anti-coagulated with EDTA. Monoclonal antibodies against $\mathrm{CD}^{+}, \mathrm{CD}^{+}, \mathrm{CD}^{+}$, and $\mathrm{CD}^{+} 6^{+}$(NK cells) were obtained from BD Company (USA). Flow cytometry was performed and the CellQuest software was used to analyze the data.

\section{Stastical analysis}

Continuous variables are expressed as means \pm SE and categorical variables as frequency or percentages. Statistical differences in basal characteristics between groups were analyzed using the $x^{2}$ test for categorical data and the twosample $t$-test for quantitative data. We used Pearson's $X^{2}$ test to compare the BT ratio in the different groups. Statistical differences between cytokines were analyzed using an analysis of variance (ANOVA) test with the $L S D$ - $t$ correction for multiple comparisons. $P$ values $<0.05$ were considered to indicate statistical significance. All analyses were conducted using the SPSS software (ver. 17.0).

\section{Results \\ Patient characteristics}

Features of the cachectic and non-cachectic patients are shown in Table 1. All patients were in stage III. No significant difference was noted in gender, age, or location between patients with cachexia and those without. Serum albumin was significantly different between the two groups $(p<0.05)$.

\section{BT rate in different groups}

Bacterial DNA fragment was detected in 12 of 50 patients with cachexia (24.0\%) and in 4 of 50 non-cachectic patients (8.0\%). None of 89 healthy controls had bacterial DNA fragments in serum. Statistically significant differences were found between cachectic and non-cachectic patients $(p=0.037,<0.05)$ and healthy controls $\left(p=0.62 \times 10^{-5},<0.05\right)$. Microorganisms identified included E. coli $(n=6)$, Staphylococcus aureus $(n=3)$, Klebsiella $(n=1)$, and Enterococcus faecalis $(n=2)$ in cachectic patients, and E. coli $(n=3)$ and Streptococcus pneumoniae $(n=1)$ in the non-cachectic patients. A representative 
Table 1. Characteristics of patients with colon cancer

\begin{tabular}{lccc}
\hline & Cachexia $(\mathrm{n}=50)$ & Non-cachexia $(\mathrm{n}=50)$ & $\mathrm{p}$ \\
\hline Gender (M/ F) & $20 / 30$ & $27 / 23$ & $0.161^{\mathrm{a}}$ \\
Age (years) & $58.5 \pm 12.0 \mathrm{~b}$ & $60.0 \pm 13.5$ & $0.719^{\mathrm{c}}$ \\
Serum albumin (g/L) & $27.5 \pm 4.4$ & $34.3 \pm 5.5$ & $<0.05^{\mathrm{c}}$ \\
Actual weight (kg) & $53.4 \pm 8.6$ & $57.6 \pm 5.3$ & $0.632^{\mathrm{c}}$ \\
Anorexia ( $\mathrm{n}$ ) & 17 & 23 & $0.221^{\mathrm{a}}$ \\
Carcinoma location & & & $0.723^{\mathrm{a}}$ \\
ascending colon & $15(30 \%)$ & $14(28 \%)$ & \\
transverse colon & $12(24 \%)$ & $10(20 \%)$ & \\
descending colon & $11(22 \%)$ & $16(32 \%)$ & \\
sigmoid colon & $12(24 \%)$ & $10(20 \%)$ & \\
\hline
\end{tabular}

a Pearson's $\chi 2$-test. b mean \pm SD (all such values). c two-sample t-test.

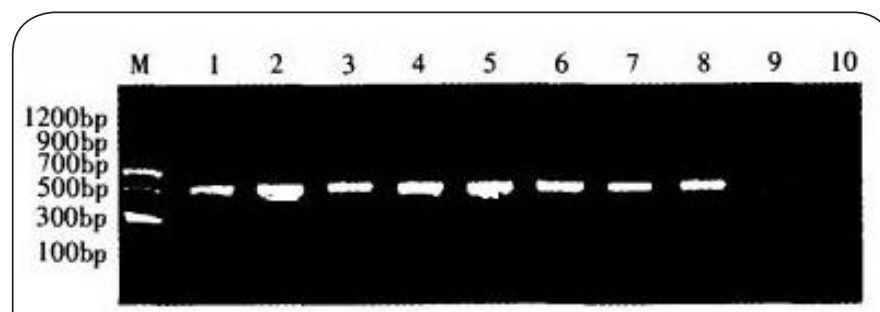

Figure 1. Agarose gel electrophoresis results from PCR. M: DNA marker, lane 1: positive control (E. coli), lanes 2-8 show an approximately 530-base pair band corresponding to lane 2-4: E. coli, lane 5: Staphylococcus aureus, lane 6: Klebsiella, lane 7: Streptococcus pneumoniae, lane 8: Enterococcus facealis, lane 9: sterile water, and lane 10: PCR mixture (with no template). photograph of a DNA agarose electrophoresis gel is shown in Figure 1.

\section{Cytokine levels in different groups}

Table 2 shows the cytokine levels in colon cancer patients and healthy controls. As seen in the table, all cytokines except IL-1 $\beta$ in $\mathrm{BT}(+)$ cachectic patients (BT(+) CP) were significantly higher than those in healthy controls $(\mathrm{HV}, p<0.001), \mathrm{BT}(+)$ noncachectic patients (BT(+) NCP, $p<0.001)$, and BT(-) cachectic patients (BT(-) CP, $p<0.001)$.

\section{Immunological indicators in cancer patients and healthy controls}

Table 3 shows the levels of T-cell subsets and NK cells in cancer patients and healthy controls. We found that $\mathrm{CD}^{+}$ $\mathrm{T}, \mathrm{CD} 4^{+} \mathrm{T}, \mathrm{CD} 4^{+} \mathrm{T} / \mathrm{CD} 8^{+} \mathrm{T}$, and NK cells were significantly lower in all colon cancer patients than in healthy controls $(p<0.05)$. The levels of $C D 8^{+} T$ cells were significantly lower in healthy controls than in colon cancer patients $(p<0.05)$.

\section{Discussion}

In the present study, we found that cachectic patients had a significantly higher rate of $B T$ than non-cachectic patients and healthy controls. Further, $\mathrm{BT}(+)$ cachectic patients had higher levels of IL-1a, IL-6, IL-8, and TNF- $a$ than BT(+) noncachectic, BT(-) cachectic patients, and healthy controls. Levels of $\mathrm{CD}^{+} \mathrm{T}, \mathrm{CD} 4^{+} \mathrm{T}, \mathrm{CD} 4^{+} \mathrm{T} / \mathrm{CD} 8^{+} \mathrm{T}$, and NK cells in colon cancer patients were lower than in healthy controls. To our knowledge, this is the first report that BT may contribute to cancer cachexia.

Table 2. Cytokine levels in patients and healthy controls $(\overline{\mathrm{x}} \pm \mathrm{s}, \mathrm{pg} / \mathrm{mL})$

\begin{tabular}{llllll}
\hline & IL- $1 \alpha$ & IL- $1 \beta$ & IL- 6 & IL- 8 & TNF- $\alpha$ \\
\hline HC $(n=89)$ & $200.1 \pm 61.4$ & $199.6 \pm 43.8$ & $42.0 \pm 6.7$ & $31.8 \pm 7.7$ & $16.4 \pm 4.4$ \\
CP & & & & & \\
BT $(+)(n=12)$ & $703.7 \pm 91.1^{* \# \$}$ & $201.2 \pm 33.3$ & $90.9 \pm 11.1^{* \# \$}$ & $115.4 \pm 22.5^{* \# \$}$ & $116.4 \pm 14.6^{* \# \$}$ \\
BT(-) $(n=38)$ & $218.7 \pm 54.1$ & $195.6 \pm 22.1$ & $38.6 \pm 5.6$ & $181.0 \pm 25.2$ & $61.5 \pm 12.4$ \\
NCP & & & & & \\
BT(+) (n=4) & $498.3 \pm 67.6$ & $216.4 \pm 76.7$ & $40.9 \pm 17.1$ & $78.8 \pm 6.2$ & $100.9 \pm 18.7$ \\
ВT(-) $(n=46)$ & $316.3 \pm 91.6$ & $220.5 \pm 65.7$ & $42.6 \pm 10.6$ & $61.4 \pm 12.9$ & $20.7 \pm 8.4$ \\
\hline
\end{tabular}

CP: cachectic patients. NCP: non-cachectic patients. HC: healthy controls. IL: interleukin. TNF: tumor necrosis factor. ${ }^{*} P<0.05 \mathrm{BT}(+) \mathrm{CP}$ vs. HC. ${ }^{*} P<0.05$ in BT(+) CP vs. BT(+) NCP. ${ }^{\$} P<0.05$ in $\mathrm{BT}(+) \mathrm{CP}$ vs. BT(-) CP.

Table 3. Results of T-cell subsets and NK cells in different groups $(\overline{\mathrm{x}} \pm \mathrm{s})$

\begin{tabular}{llllll}
\hline & $\mathrm{CD}^{+} \mathrm{T}(\%)$ & $\mathrm{CD}^{+} \mathrm{T}(\%)$ & $\mathrm{CD}^{+} \mathrm{T}(\%)$ & $\mathrm{CD}^{+}{ }^{+} \mathbf{T} / \mathrm{CD}^{+} \mathrm{T}$ & $\mathrm{NK}(\%)$ \\
\hline $\mathrm{HC}$ & $40.73 \pm 5.70$ & $66.73 \pm 5.94$ & $47.21 \pm 6.09$ & $1.55 \pm 0.24$ & $30.69 \pm 4.28$ \\
$\mathrm{CCP}$ & $36.39 \pm 5.99^{*}$ & $60.25 \pm 5.31^{*}$ & $55.38 \pm 5.80^{*}$ & $1.23 \pm 0.22^{*}$ & $27.95 \pm 3.68^{*}$ \\
\hline
\end{tabular}

HC: healthy controls. CCP: colon cancer patients (includes cachectic and non-cachectic patients). ${ }^{*} p<0.05$. 
To date, the mechanism of $\mathrm{BT}$ is not completely understood. Major factors inducing BT may include an imbalance in intestinal microflora, intestinal mucosal barrier dysfunction, and host immune impairment. These determinants of BT should be viewed as interrelated, interacting with each other [17]. In our study, although we did not investigate alterations in intestinal microflora or mucosal barrier dysfunction, it has been reported that colon cancer patients display an increase in aerobic bacteria and a decrease in anaerobic species [18]. Dysfunction of the mucosal barrier in colon cancer patients has also been reported [19]. Regarding the third factor, we found that levels of $\mathrm{CD}^{+} \mathrm{T}, \mathrm{CD} 4^{+} \mathrm{T}, \mathrm{CD} 4^{+} / \mathrm{CD}^{+} \mathrm{T}$, and NK cells were significantly lower in colon cancer patients, indicating immune dysfunction in the patients, consistent with previous reports $[\mathbf{2 0}, \mathbf{2 1}]$. Moreover, we found that the BT ratio was significantly higher in cachectic patients than in non-cachectic patients and healthy controls. Additionally, levels of IL-1a, IL-6, IL-8, and TNF-a were significantly higher in $\mathrm{BT}(+)$ cachectic patients than in $\mathrm{BT}(-)$ cachectic patients, $\mathrm{BT}(+)$ non-cachectic patients, and healthy controls.

Considering that the patients enrolled in our study had no obvious exogenous infection, endogenous infection or bacterial translocation may play an important role in cytokine secretion. It is worth noting that there is a distinction between limited bacterial invasion and septicemia, which is a serious medical condition that can be life-threatening. Septicemia is caused by bacteria that enter the bloodstream, triggering an immune response, resulting in inflammation and a slow shutdown of the body's systems for handling infection. The microorganisms usually spread to other organs, such as the lungs, liver, and brain. However, the patients enrolled in the present study had no clinical exogenous infection, such as infection of the lung, urinary tract, central nervous system, or heart. Above all, there were no systemic symptoms of septicemia in these patients. Thus, we could not make a diagnosis of septicemia although bacterial DNA was detected in the blood. Also, we did not culture bacteria because symptoms of infection were not seen. The results of the present study suggest that bacterial invasion may contribute to cachexia. Thus, it may be that translocated bacteria (a limited bacterial invasion) occur because patients with cancer could not clear them due to their low immunity; they could then propagate and cause cytokine secretion increases. Proinflammatory cytokines raise the rate of metabolism and suppress appetite, so the body weight of the patients decreased gradually and cachexia occured.

There are some limitations and strengths to the present study. Currently, techniques for the detection of bacterial translocation primarily include bacterial culture from mesenteric lymph nodes and PCR for bacterial DNA detection. Reddy and colleagues [22] used bacterial cultures to identify the origins and nature of translocated bacteria. This method provides live bacteria but may give false-negative results, to some extent, and is time-consuming. In the present study, we used PCR to detect bacterial DNA and found that the BT ratio was up to $24 \%$ in cachectic patients. Although a PCR approach can lead to false-positive results and requires strict laboratory controls, it is a highly sensitive and specific method for detecting bacterial DNA, as addressed by Ono et al. [23], Certainly, better methods need to be explored in the future.

\section{Conclusions}

In summary, the present study, in a Chinese population, indicated that BT may contribute to the occurrence and development of cancer cachexia. Studies with larger sample sizes and examining the route(s) of bacterial translocation are needed to further determine the role of BT in cancer cachexia.

\section{Competing interests}

The authors declare that they have no competing interests.

\section{Author contributions}

JZ, LM, YJW and DLZ were all involved in designing the study. All authors reviewed the data and were involved in the final analysis and conclusions. JZ wrote the first draft of the manuscript. JZ, LM, YJW were equally as the first authour. All authors read and approved the final manuscript.

\section{Author information}

Corresponding author Diangliang Zhang has been studying cancer cachexia for more than 10 years. He has reported some outstanding results in this area: for example, (1) Zhang DL, Zheng HM, Zhou YB, Yu BJ, Li JS. Association of IL-1 $\beta$ gene polymorphism with cachexia from locally advanced gastric cancer. BMC Cancer. 2007;3.1-7. (2) Dianliang Z. Probing cancer cachexia-anorexia: recent results with knockout, transgene and polymorphisms. Curr Opin Clin Nutr Metab Care. 2009 May;12(3):227-31. He became a member of the Association of Clinical Scientists in May 2011 because of his achievements.

\section{Acknowledgments \& Funding}

This research was supported, in part, by grants from Shandong Natural Foundation (ZR2010HM122) and the Key Project of Shandong Scientific and Technology (2008GG30002034).

\section{Publication history}

Editor: Vincent Lee Wilson, Louisiana State University, USA. EIC: G.J. Peters, VU University Medical Center, Netherlands. Received: 22-May-2012 Revised: 20-June-2012 Re-Revised: 19-July-2012 Accepted: 30-July-20112 Published: 07-Aug-2012

\section{References}

1. Muscaritoli M, Bossola M, Aversa Z, Bellantone R, Rossi Fanelli $F$ : Prevention and treatment of cancer cachexia: new insights into an old problem. Eur J Cancer 2006; 42;(1.);31-41. I Article I PubMed

2. Lelbach A, Muzes G, Feher J: Current perspectives of catabolic mediators of cancer cachexia. Med Sci Monit 2007; 13;(9.);RA168-73. | Article I PubMed

3. Tisdale MJ: Biomedicine. Protein loss in cancer cachexia. Science 2000; 289;(5488.);2293-4. | Article | PubMed

4. Argiles JM, Busquets S, Garcia-Martinez C, Lopez-Soriano FJ: Mediators involved in the cancer anorexia-cachexia syndrome: past, present, and future. Nutrition 2005; $21 ;(9.) ; 977-85$. । 
Article I PubMed

5. Saini A, Al-Shanti N, Stewart CE: Waste management - cytokines, growth factors and cachexia. Cytokine Growth Factor Rev 2006; 17;(6.);475-86. | Article I PubMed

6. Tisdale MJ: Metabolic abnormalities in cachexia and anorexia. Nutrition 2000; 16;(10.);1013-4. | Article | PubMed

7. Stephens NA, Skipworth RJ, Fearon KC: Cachexia, survival and the acute phase response. Curr Opin Support Palliat Care 2008; 2;(4.);267-74. | Article | PubMed

8. Penna F, Minero VG, Costamagna D, Bonelli G, Baccino FM, Costelli P: Anti-cytokine strategies for the treatment of cancerrelated anorexia and cachexia. Expert Opin Biol Ther 2010; 10;(8.);1241-50. I Article I PubMed

9. Kemik O, Sumer A, Kemik AS, Hasirci I, Purisa S, Dulger AC, et al.: The relationship among acute-phase response proteins, $c y-$ tokines and hormones in cachectic patients with colon cancer. World J Surg Oncol 2010; 8;(85. | Article | PubMed Abstract | PubMed Full Text

10. Johnen H, Lin S, Kuffner T, Brown DA, Tsai VW, Bauskin AR, et al.: Tumor-induced anorexia and weight loss are mediated by the TGF-beta superfamily cytokine MIC-1. Nat Med 2007; 13;(11.);1333-40. | Article | PubMed

11. Gencay C, Kilicoglu SS, Kismet K, Kilicoglu B, Erel S, Muratoglu S, et al.: Effect of honey on bacterial translocation and intestinal morphology in obstructive jaundice. World J Gastroenterol 2008; 14;(21.);3410-5. I Article I PubMed Abstract I PubMed Full Text

12. Gatt M, Reddy BS, MacFie J: Review article: bacterial translocation in the critically ill--evidence and methods of prevention. Aliment Pharmacol Ther 2007; 25;(7.);741-57. | Article | PubMed

13. DeMeo MT, Mutlu EA, Keshavarzian A, Tobin MC: Intestinal permeation and gastrointestinal disease. J Clin Gastroenterol 2002; 34;(4.);385-96. | Article I PubMed

14. Wiest R, Rath HC: Gastrointestinal disorders of the critically ill. Bacterial translocation in the gut. Best Pract Res Clin Gastroenterol 2003; 17;(3.);397-425. | Article I PubMed

15. Frances R, Gonzalez-Navajas JM, Zapater P, Munoz C, Cano R, Pascual $S$, et al.: Translocation of bacterial DNA from Grampositive microorganisms is associated with a species-specific inflammatory response in serum and ascitic fluid of patients with cirrhosis. Clin Exp Immunol 2007; 150;(2.);230-7. I Article | PubMed Abstract | PubMed Full Text

16. Such J, Frances R, Munoz C, Zapater P, Casellas JA, Cifuentes A, et al.: Detection and identification of bacterial DNA in patients with cirrhosis and culture-negative, nonneutrocytic ascites. Hepatology 2002; 36;(1.);135-41. | Article | PubMed

17. Wiest R. Bacterial Translocation. Bios Micro 2005; 24; 61-90.

18. Niu H, Bao W, Gong KM, Liu WJ, Hu DC, et al. The Comparative Research on Intestinal Flora Population of Patients with Colorectal Cancer and Normal People. J Kunming Medi Colle 2009; 12: 97-100.

19. Soler AP, Miller RD, Laughlin KV, Carp NZ, Klurfeld DM, Mullin JM: Increased tight junctional permeability is associated with the development of colon cancer. Carcinogenesis 1999; 20;(8.);1425-31. | Article I PubMed

20. Qiu HB, Wu XJ, Zhou ZW, Wan DS, Chen G, Lu ZH, et al. Change and significance of T-cell subgroup and Nk-cell in peripheral blood of patients with colorectal cancer. Guangdong Medi J 2009; 30; 447-9.

21. Enarsson $\mathrm{K}$, Lundin BS, Johnsson E, Brezicka T, Quiding-Jarbrink $\mathrm{M}$ : CD4+ CD25high regulatory $\mathrm{T}$ cells reduce $\mathrm{T}$ cell transendothelial migration in cancer patients. Eur J Immunol 2007; 37;(1.);282-91. I Article | PubMed

22. Reddy BS, MacFie J, Gatt M, Macfarlane-Smith L, Bitzopoulou K, Snelling AM: Commensal bacteria do translocate across the intestinal barrier in surgical patients. Clin Nutr 2007; 26;(2.);20815. | Article | PubMed

23. Ono S, Tsujimoto H, Yamauchi A, Hiraki S, Takayama E, Mochizuki H: Detection of microbial DNA in the blood of surgical patients for diagnosing bacterial translocation. World J Surg 2005; 29;(4.);535-9. I Article I PubMed 